Research Paper

\title{
Dysregulated expression of homeobox family genes may influence survival outcomes of patients with epithelial ovarian cancer: analysis of data from The Cancer Genome Atlas
}

\author{
Kyung Jin Eoh ${ }^{1}$, Hee Jung Kim ${ }^{1}$, Jung-Yun Lee ${ }^{1}$, Eun Ji Nam ${ }^{1}$, Sunghoon Kim ${ }^{1}$, Sang \\ Wun $\mathrm{Kim}^{1}$ and Young Tae Kim ${ }^{1}$ \\ ${ }^{1}$ Institute of Women's Medical Life Science, Department of Obstetrics and Gynecology, Yonsei University College of Medicine, \\ Seoul, Korea \\ Correspondence to: Young Tae Kim, email: ytkchoi@yuhs.ac \\ Keywords: carcinogenesis, epithelial ovarian cancer, homeobox genes, survival, TCGA \\ Received: June 11,2017 Accepted: June 30,2017 Published: August 01, 2017 \\ Copyright: Eoh et al. This is an open-access article distributed under the terms of the Creative Commons Attribution License 3.0 \\ (CC BY 3.0), which permits unrestricted use, distribution, and reproduction in any medium, provided the original author and source \\ are credited.
}

\section{ABSTRACT}

Homeobox (HOX) family genes encode key transcription factors for embryogenesis and may be correlated with carcinogenesis. The aim of this study was to elucidate whether aberrant expression of HOX genes influences outcomes in epithelial ovarian cancer (EOC). Gene expression data and clinicopathologic information from $\mathbf{6 3 0}$ patients with EOC were downloaded from The Cancer Genome Atlas database. We explored correlations between expression levels of HOX gene family members and clinicopathological variables. Higher expression of HOXA1, A4, A5, A7, A10, A11, $B 13, C 13, D 1$, and $D 3$ was associated with advanced FIGO stage. Suboptimal residual disease after debulking surgery was significantly correlated with higher expression of HOXB9, B13, and C13. Additionally, patients with high expression of HOXC6 and C11 were significantly more likely to have poor performance status. Overall survival was significantly shorter in patients with high, rather than low, expression of two HOX genes (HOXA10 and B3), and significantly longer in patients with high rather than low HOXC5 expression. Dysregulated expression of the HOXA10, B3, and C5 was significantly correlated with overall survival in EOC patients. HOX gene expression levels are potentially useful as a prognostic indicator in EOC, and HOX genes may represent a novel and promising target for anticancer therapeutics.

\section{INTRODUCTION}

Epithelial ovarian cancer (EOC), the leading cause of gynecologic cancer-related mortality, is known to be a multifactorial disease involving genetic, environmental, and epigenetic factors [1,2]. Recently, research has focused on aberrant variation in the expression of transcription factors and its importance in the development of this malignancy [3].

Homeobox (HOX) genes, defined by a highly conserved 183-base pair DNA sequence called the homeobox, encode homeoproteins that function as transcription factors in differentiation and proliferation processes during embryonic structural development [4].
Aberrant expression of these proteins has been associated with carcinogenesis and aggressiveness [5, 6]. This is consistent with the idea that expression levels of many genes involved in normal embryogenesis are aberrant in various malignancies [7].

Previous studies showed that dysregulation of several $H O X$ genes (including aberrant expression of HOXA7, HOXA9, HOXC8, HOXB13, and HOXC6) was associated with adverse prognostic factors in EOC; however, the majority of this research was limited by small sample sizes and was performed only in vitro [8-14]. Several studies have shown potential roles for HOX antisense long non-coding RNAs in ovarian cancer aggressiveness $[15,16]$. These results suggest that aberrant 
expression of $H O X$ genes may be correlated with the process of ovarian cancer carcinogenesis.

We analyzed the mRNA expression level of all 39 HOX genes using data from The Cancer Genome Atlas (TCGA) database on epithelial ovarian cancer and explored correlations with clinical data, including survival outcomes. We also evaluated the prognostic value of $H O X$ gene expression analysis.

\section{RESULTS}

In total, we included 630 ovarian cancer cases, which were all the patients who included in the TCGA ovarian cancer database. The median follow-up period was 34.0 months (range, 0.3-182.7 months). Among clinicopathological features, age at the time of diagnosis, advanced Federation of Gynecology and Obstetrics (FIGO) stage, suboptimal residual disease, and poor Eastern Cooperative Oncology Group (ECOG) performance status were found to be independent predictive factors for overall survival in multivariate Cox regression analysis (Table 1 ).

Table 2 shows correlations between clinicopathological features and mRNA expression levels of $H O X$ family genes. When the cases were categorized into low and high mRNA expression groups based on cut-off values determined as the median for each gene, higher expression of HOXA1 $(\mathrm{P}=0.011), A 4(\mathrm{P}=0.045)$, $A 5(\mathrm{P}=0.01), A 7(\mathrm{P}=0.047), A 10(\mathrm{P}=0.009), A 11(\mathrm{P}=$ $0.001), B 13(\mathrm{P}=0.01), C 13(\mathrm{P}=0.022), D 1(\mathrm{P}=0.004)$, and $D 3(\mathrm{P}=0.011)$ was associated with advanced FIGO stage. Suboptimal residual disease after debulking surgery was significantly correlated with higher expression of HOXB9 $(\mathrm{P}=0.002), B 13(\mathrm{P}=0.008)$, and C13 $(\mathrm{P}=0.04)$. In addition, patients with high expression of $H O X C 6(\mathrm{P}=$ $0.018)$ and $C 11(\mathrm{P}=0.049)$ were significantly more likely to have poor performance status (ECOG 2 or 3 ).

Out of the total 630 patients, 584 patients $(92.7 \%)$ had information on both prognostic value and microarray for the transcriptome analysis, so the prognosis of the 584 patients was analyzed. Kaplan-Meier survival analysis showed that overall survival (OS) was significantly shorter in patients with high rather than low expression levels of HOXA10 ( $\mathrm{P}=0.008$, median OS: 36 vs. 32 months) and HOXB3 ( $\mathrm{P}=0.003$, median OS: 34 vs. 32 months), and significantly longer in patients with high rather than low HOXC5 expression ( $\mathrm{P}=0.022$, median OS: 33 vs. 35 months) (Figure 1). Multivariate Cox regression analysis of $H O X$ gene expression also demonstrated that HOXA10 and $H O X B 3$ were significant positive predictive factors [odds ratio (OR): 1.305 and 1.462, 95\% confidence interval (CI): 1.052-1.619 and 1.174-1.822, respectively], while $H O X C 5$ (OR: $0.713,95 \%$ CI: 0.572-0.889) was a significant negative predictive factor for overall survival (Figure 2).

\section{DISCUSSION}

In this study, we demonstrated that increased mRNA expression of certain $H O X$ genes was independently associated with multiple risk factors, including advanced FIGO stage, suboptimal residual disease, and poor performance status, that were found to influence survival outcomes in ovarian cancer using the TCGA database. Specifically, upregulation of $H O X A 10$ and $\mathrm{HOXB3}$ genes and downregulation of $\mathrm{HOXC5}$ were significantly associated with unfavorable survival outcomes in patients with ovarian cancer.

Accumulating evidence indicates that $H O X$ genes may be useful biomarkers to predict and evaluate responses to chemotherapy [17]. Our results were not completely consistent with those of previous in vitro research. In particular, the clinical relevance of $H O X B 3$ and $H O X C 5$ was not known until now. This might be explained by the fact that the majority of studies reported to date have been retrospective in nature or conducted in small sized patient cohorts. To the best of our knowledge, this is the first study of $H O X$ genes performed using clinical data from TCGA database. Also, it is feasible to clinically classify each subtype to determine the prognosis based on the results of this study. Further functional studies are required to identify the specific mechanisms by which $H O X$ gene dysregulation influences oncogenesis.

During embryogenesis, as well as in adult tissues, growth, differentiation, and organization of cell populations are tightly coordinated and controlled [18]. In contrast, cancer has been identified as aberrations of these basic processes [19]. The oncogerminative theory of carcinogenesis suggests that malignant transformation is due to the aberrant expression of embryogenesis-related genes [20]. According to this concept, carcinogenesis is a dynamic self-organizing process that is similar to the process of early embryo development. Additionally, the malignant transformation that arises from gene mutations, in combination with epigenetic dysregulation, may reprogram somatic cells into immortal cells that simulate germline cells; this is consistent with cancer stem cells [20].

A substantial body of evidence supports a crucial role for HOX genes as developmental genes during embryogenesis, and also supports the critical role of aberrant $H O X$ gene expression in the development of various tumors, specifically in ovarian cancer $[5-7,17$, $21,22]$. Further research is needed to elucidate all roles of $H O X$ genes in ovarian cancer. A major limitation of this study is the short-term follow-up period, and the small number of overall mortalities during the period might weaken the clinical applicability of the current findings. A more comprehensive investigation is promising in the further analysis based on the regularly updated TCGA data in the future. Although this study proved the hypothesis 
Table 1: Correlation between clinicopathological features and overall mortality

\begin{tabular}{|c|c|c|c|}
\hline \multirow{2}{*}{ Variables } & \multirow{2}{*}{ Total $n=630 n(\%)$} & \multicolumn{2}{|c|}{ Multivariate analysis } \\
\hline & & HR $(95 \%$ CI $)$ & $\mathbf{P}$ \\
\hline \multicolumn{4}{|l|}{ Age } \\
\hline$<45$ & $54(8.6)$ & 1 (Reference) & 0.042 \\
\hline$\geq 45$ & $553(87.8)$ & $1.512(0.991-2.309)$ & \\
\hline N/A & $23(3.7)$ & & \\
\hline \multicolumn{4}{|l|}{ Stage } \\
\hline I & $18(2.9)$ & 1 (Reference) & 0.002 \\
\hline II & $33(5.2)$ & & \\
\hline III & $462(73.3)$ & $2.264(1.272-4.029)$ & \\
\hline IV & $89(14.1)$ & & \\
\hline N/A & $28(4.4)$ & & \\
\hline \multicolumn{4}{|l|}{ Histology } \\
\hline Serous & $607(96.3)$ & & \\
\hline N/A & $23(3.7)$ & & \\
\hline \multicolumn{4}{|l|}{ Grade } \\
\hline 1,2 & $85(13.5)$ & 1 (Reference) & 0.253 \\
\hline 3,4 & $505(80.2)$ & $1.189(0.884-1.598)$ & \\
\hline N/A & $40(6.3)$ & & \\
\hline \multicolumn{4}{|c|}{ LN metastasis } \\
\hline No & $85(13.5)$ & 1 (Reference) & 0.125 \\
\hline Yes & $139(22.1)$ & $1.387(0.913-2.107)$ & \\
\hline N/A & $406(64.4)$ & & \\
\hline \multicolumn{4}{|c|}{ Residual disease } \\
\hline$\leq 1 \mathrm{~cm}$ & $387(61.4)$ & 1 (Reference) & $<0.001$ \\
\hline$\leq 2 \mathrm{~cm}$ & $151(24.0)$ & $1.548(1.222-1.960)$ & \\
\hline N/A & $92(14.6)$ & & \\
\hline \multicolumn{4}{|l|}{ ECOG } \\
\hline 0,1 & $123(19.5)$ & 1 (Reference) & 0.002 \\
\hline 2,3 & $12(1.9)$ & $3.317(1.552-7.087)$ & \\
\hline N/A & $495(78.6)$ & & \\
\hline
\end{tabular}

N/A, not available; ECOG, The Eastern Cooperative Oncology Group performance status; HR, hazard ratio; CI, confidence interval; LN, lymph node.

that dysregulated expression of $H O X$ genes, based on microarray data, was correlated with altered survival outcomes in EOC, further validation using a different modality, such as large-volume RNA sequencing or immunohistochemical assay, might also be needed to verify the current results.
Analyzing $H O X$ gene expression levels in a cytologic or surgical specimen can facilitate the selection of patients with ovarian cancer who are expected to have a poor prognosis. Based on analytical results, we can prescribe more aggressive treatment or more frequent follow-up for cases with an expected high risk. Moreover, 
Table 2: Summary of the correlation between clinicopathological features and mRNA expression counts of homeobox $(H O X)$ family genes

\begin{tabular}{|c|c|c|c|c|c|}
\hline Age $\geq 45$ & Stage III/IV & Grade 3/4 & LN metastasis & Residual disease $>1 \mathrm{~cm}$ & ECOG 2, 3 \\
\hline HOXA1 & + & & & & \\
\hline \multicolumn{6}{|l|}{ HOXA2 } \\
\hline HOXA3 & & & + & & \\
\hline HOXA4 & + & & & & \\
\hline HOXA5 & + & & + & & \\
\hline \multicolumn{6}{|l|}{ HOXА } \\
\hline HOXA7 & + & & & & \\
\hline \multicolumn{6}{|l|}{ HOXАЯ } \\
\hline HOXA10 & ++ & & & & \\
\hline HOXA11 & ++ & & + & & \\
\hline \multicolumn{6}{|l|}{ HOXA13 } \\
\hline \multicolumn{6}{|l|}{$H O X B 1$} \\
\hline HOXB2 & & & ++ & & \\
\hline HOXB3 & & + & & & \\
\hline \multicolumn{6}{|l|}{ HOXB4 } \\
\hline \multicolumn{6}{|l|}{ HOXB5 } \\
\hline \multicolumn{6}{|l|}{ НОХВ6 } \\
\hline \multicolumn{6}{|l|}{$H O X B 7$} \\
\hline \multicolumn{6}{|l|}{$H O X B 8$} \\
\hline HOXB9 & & & & ++ & \\
\hline$H O X B 13$ & + & & & ++ & \\
\hline \multicolumn{6}{|l|}{$\mathrm{HOXC4}$} \\
\hline \multicolumn{6}{|l|}{ HOXC5 } \\
\hline HOXC6 & & & & & + \\
\hline \multicolumn{6}{|l|}{ HOXC8 } \\
\hline \multicolumn{6}{|l|}{ НОХСР } \\
\hline \multicolumn{6}{|l|}{ HOXC10 } \\
\hline $\mathrm{HOXC11}$ & & & & & + \\
\hline \multicolumn{6}{|l|}{$\mathrm{HOXC} 12$} \\
\hline HOXC13 & + & & & + & \\
\hline$H O X D 1$ & ++ & & & & \\
\hline HOXD3 & + & ++ & & & \\
\hline \multicolumn{6}{|l|}{ HOXD4 } \\
\hline \multicolumn{6}{|l|}{ HOXD8 } \\
\hline \multicolumn{6}{|l|}{ HOXD9 } \\
\hline \multicolumn{6}{|l|}{$H O X D 10$} \\
\hline HOXD11 & & & ++ & & \\
\hline$H O X D 12$ & & & ++ & & \\
\hline HOXD13 & & + & & & \\
\hline
\end{tabular}

+ , Correlation with $\mathrm{P}$ value $<0.05$; ++, correlation with $\mathrm{P}$ value $<0.01$; LN, lymph node; ECOG, The Eastern Cooperative Oncology Group performance status. 
(A)

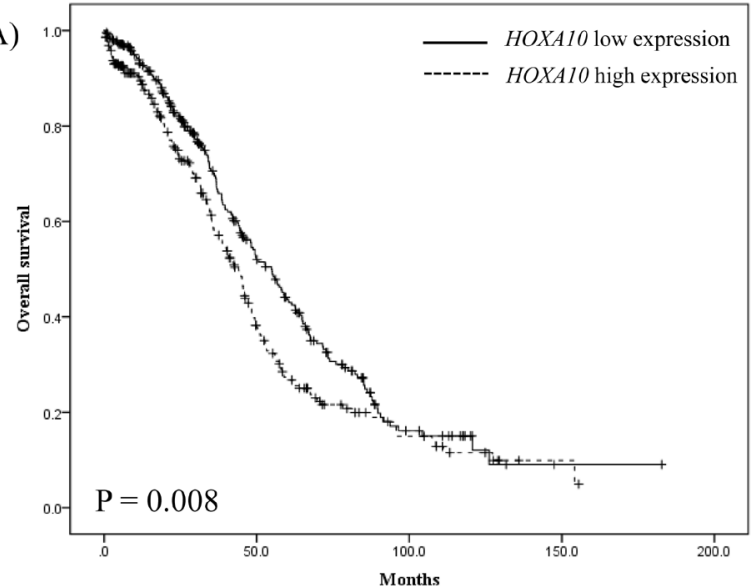

(C)

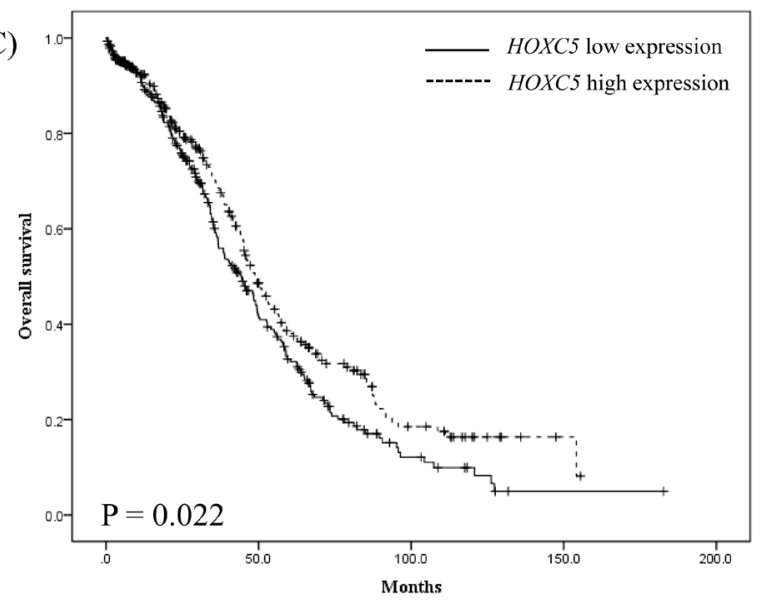

(B)

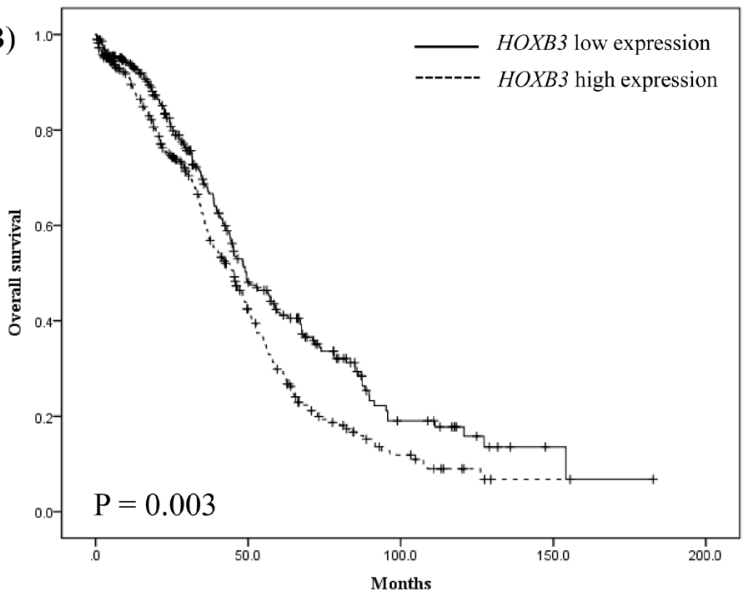

Figure 1: Kaplan-Meier survival analysis of 584 patients with ovarian cancer stratified by (A) HOXA10, (B) HOXB3, and (C) HOXC5 gene expression levels on microarray.

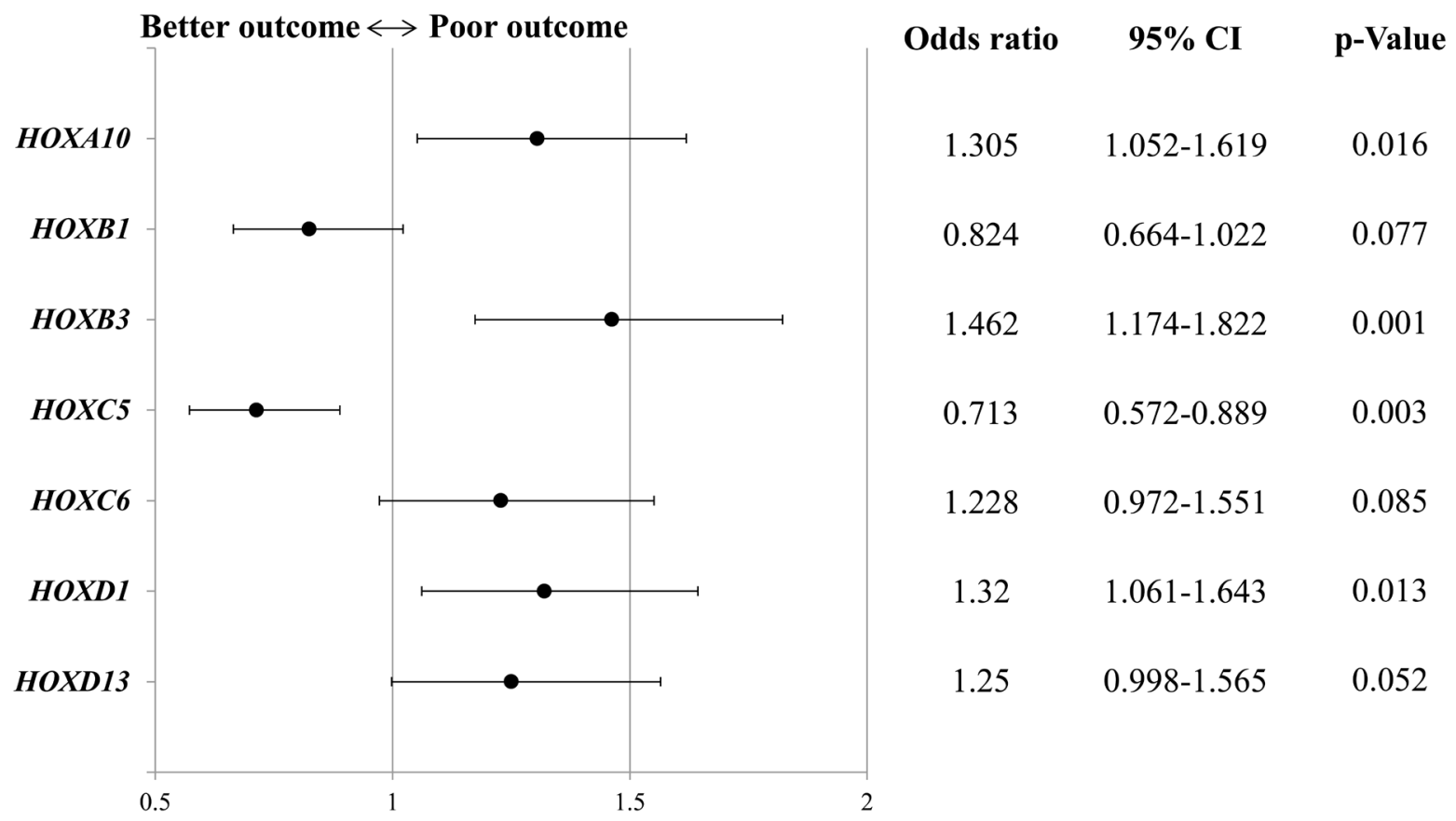

Figure 2: Multivariate analyses of homeobox $(\mathrm{HOX})$ gene expression predicting overall survival. $\mathrm{CI}$, confidence interval. 
there are great unmet needs of patients with refractory ovarian cancer that recurs after treatment with standard therapy, which demands novel therapeutic agents. Drugs regulating $H O X$ gene expression could potentially have a therapeutic effect by inducing inhibition of reprogramed oncogerminative cells, as was shown by in vitro experiments using a homeobox transcription factor inhibitor [23]. Recently, decitabine, a drug that induced $\mathrm{CpG}$ island hypomethylation of HOXA10 and HOXA11 genes, showed significant correlation with improved progression-free survival in an open-label, single-center, phase II clinical trial [24].

In conclusion, dysregulated expression of the $H O X A 10, H O X B 3$, and $H O X C 5$ genes was significantly associated with favorable or unfavorable overall survival in a large ovarian cancer cohort from TCGA. Additionally, many of the $H O X$ genes were correlated with clinical variables that were independent predictive factors for overall survival. Evaluation of $H O X$ gene expression may be potentially valuable as a marker to predict prognosis in serous ovarian cancer.

\section{MATERIALS AND METHODS}

\section{Data acquisition}

We collected mRNA expression data for $39 \mathrm{HOX}$ family genes and corresponding clinicopathological information from the TCGA data portal (https://tcga-data. nci.nih.gov/tcga/tcgaDownload.jsp). The patient personal information is anonymized and deidentified. According to the TCGA publication guidelines (http://cancergenome. nih.gov/publications/publicationguidelines), these mRNA sequencing data have no restrictions on publication, and no additional approval by an ethics committee was required to publish findings utilizing the data. The database compiled from microarray analysis performed using GeneChip Human Genome U133A 2.0 Array (Affymetrix) was analyzed in this study.

\section{Patient information}

We obtained the mRNA expression levels of 39 $H O X$ family genes for each patient, along with their clinicopathologic features, including age at initial pathologic diagnosis, International FIGO stage, histologic subtype, lymph node metastasis, and overall survival (Supplementary Table 1).

\section{Statistical analyses}

We used the Fisher exact or $\chi 2$ tests for categorical variables, according to sample size. Linear regression was applied to assess associations between clinical variables and each $H O X$ gene expression count. Medians of $H O X$ gene expression were determined as the cut-off value for prediction of survival. Kaplan-Meier survival analyses and multivariate Cox regression analysis based on the calculated cut-off values were performed. SPSS version 23.0 (IBM Corp., Armonk, NY, USA) was used for data analysis.

\section{Abbreviations}

HOX, homeobox; TCGA, The Cancer Genome Atlas; EOC, epithelial ovarian cancer; OR, odds ratio; CI, confidence interval; FIGO, Federation of Gynecology and Obstetrics; N/A, not available; ECOG, The Eastern Cooperative Oncology Group performance status

\section{Author contributions}

Conception \& Design of Study was done by KJE, HJK, JYL, EJN, SK, SWK and YTK. Data Collection was done by KJE. Data Analysis \& Interpretation was done by KJE and YTK. Statistical Analysis was done by KJE. Manuscript Preparation was done by KJE, and YTK.

\section{ACKNOWLEDGMENTS}

This work was supported by the Basic Science Research Program through the National Research Foundation of Korea (NRF) funded by the Ministry of Education, Science, and Technology (grant numbers NRF-2015R1A2A2A01008162 and NRF2015R1C1A2A01053516).

\section{CONFLICTS OF INTEREST}

The authors report no conflicts of interest.

\section{FINANCIAL SUPPORT}

None

\section{REFERENCES}

1. Siegel RL, Miller KD, Jemal A. Cancer statistics, 2016. CA Cancer J Clin. 2016; 66: 7-30. https://doi.org/10.3322/ caac. 21332.

2. Rai A, Pradhan P, Nagraj J, Lohitesh K, Chowdhury R, Jalan S. Understanding cancer complexome using networks, spectral graph theory and multilayer framework. Sci Rep. 2017; 7: 41676. https://doi.org/10.1038/srep41676.

3. Wang LL, Xiu YL, Chen X, Sun KX, Chen S, Wu DD, Liu BL, Zhao Y. The transcription factor FOXA1 induces epithelial ovarian cancer tumorigenesis and progression. Tumour Biol. 2017; 39. https://doi. org/10.1177/1010428317706210. 
4. Daftary GS, Taylor HS. Endocrine regulation of HOX genes. Endocr Rev. 2006; 27: 331-55. https://doi. org/10.1210/er.2005-0018.

5. Gehring WJ, Hiromi Y. Homeotic genes and the homeobox. Annu Rev Genet. 1986; 20: 147-73. https://doi.org/10.1146/ annurev.ge.20.120186.001051.

6. Haria D, Naora H. Homeobox gene deregulation: impact on the hallmarks of cancer. Cancer Hallm. 2013; 1: 67-76. https://doi.org/10.1166/ch.2013.1007.

7. Abate-Shen C. Deregulated homeobox gene expression in cancer: cause or consequence? Nat Rev Cancer. 2002; 2: 777-85. https://doi.org/10.1038/nrc907.

8. Chong GO, Jeon HS, Han HS, Son JW, Lee YH, Hong DG, Park HJ, Lee YS, Cho YL. Overexpression of microRNA$196 \mathrm{~b}$ accelerates invasiveness of cancer cells in recurrent epithelial ovarian cancer through regulation of homeobox A9. Cancer Genomics Proteomics. 2017; 14: 137-41. https://doi.org/10.21873/cgp.20026.

9. Lu S, Liu R, Su M, Wei Y, Yang S, He S, Wang X, Qiang F, Chen C, Zhao S, Qian L, Shao M, Mao G. Overexpression of HOXC8 is associated with poor prognosis in epithelial ovarian cancer. Reprod Sci. 2016; 23: 944-54. https://doi. org/10.1177/1933719115625845.

10. Yuan H, Kajiyama H, Ito S, Chen D, Shibata K, Hamaguchi M, Kikkawa F, Senga T. HOXB13, ALX4 induce SLUG expression for the promotion of EMT and cell invasion in ovarian cancer cells. Oncotarget. 2015; 6: 13359-70. https:// doi.org/10.18632/oncotarget.3673.

11. Tait DL, Bahrani-Mostafavi Z, Vestal CG, Richardson C, Mostafavi MT. Downregulation of HOXC6 in serous ovarian cancer. Cancer Invest. 2015; 33: 303-11. https:// doi.org/10.3109/07357907.2015.1041641.

12. Ko SY, Naora H. HOXA9 promotes homotypic and heterotypic cell interactions that facilitate ovarian cancer dissemination via its induction of P-cadherin. Mol Cancer. 2014; 13: 170. https://doi.org/10.1186/1476-4598-13-170.

13. Ko SY, Ladanyi A, Lengyel E, Naora H. Expression of the homeobox gene HOXA9 in ovarian cancer induces peritoneal macrophages to acquire an M2 tumor-promoting phenotype. Am J Pathol. 2014; 184: 271-81. https://doi. org/10.1016/j.ajpath.2013.09.017.

14. Naora H, Montz FJ, Chai CY, Roden RB. Aberrant expression of homeobox gene HOXA7 is associated with mullerian-like differentiation of epithelial ovarian tumors and the generation of a specific autologous antibody response. Proc Natl Acad Sci U S A. 2001; 98: 15209-14. https://doi.org/10.1073/pnas.011503998.

15. Yim GW, Kim HJ, Kim LK, Kim SW, Kim S, Nam EJ, Kim YT. Long non-coding RNA HOXA11 antisense promotes cell proliferation and invasion and predicts patient prognosis in serous ovarian cancer. Cancer Res Treat. 2017; 49: 656-68. https://doi.org/10.4143/crt.2016.263.

16. Richards EJ, Permuth-Wey J, Li Y, Chen YA, Coppola D, Reid BM, Lin HY, Teer JK, Berchuck A, Birrer MJ, Lawrenson K, Monteiro AN, Schildkraut JM, et al. A functional variant in HOXA11-AS, a novel long noncoding RNA, inhibits the oncogenic phenotype of epithelial ovarian cancer. Oncotarget. 2015; 6: 34745-57. https://doi. org/10.18632/oncotarget.5784.

17. Miller KR, Patel JN, Ganapathi MK, Tait DL, Ganapathi RN. Biological role and clinical implications of homeobox genes in serous epithelial ovarian cancer. Gynecol Oncol. 2016; 141: 608-15. https://doi.org/10.1016/j. ygyno.2016.03.004.

18. Vinnitsky VB. Oncogerminative hypothesis of tumor formation. Med Hypotheses. 1993; 40: 19-27. https://doi. org/10.1016/0306-9877(93)90191-R.

19. Negrini S, Gorgoulis VG, Halazonetis TD. Genomic instability--an evolving hallmark of cancer. Nat Rev Mol Cell Biol. 2010; 11: 220-8. https://doi.org/10.1038/ nrm2858.

20. Vinnitsky V. The development of a malignant tumor is due to a desperate asexual self-cloning process in which cancer stem cells develop the ability to mimic the genetic program of germline cells. Intrinsically Disord Proteins. 2014; 2: e29997. https://doi.org/10.4161/idp.29997.

21. Kelly Z, Moller-Levet C, McGrath S, Butler-Manuel S, Kavitha Madhuri T, Kierzek AM, Pandha H, Morgan R, Michael A. The prognostic significance of specific HOX gene expression patterns in ovarian cancer. Int $\mathrm{J}$ Cancer. 2016; 139: 1608-17. https://doi.org/10.1002/ijc.30204.

22. Kar SP, Tyrer JP, Li Q, Lawrenson K, Aben KK, AntonCulver H, Antonenkova N, Chenevix-Trench G, Baker H, Bandera EV, Bean YT, Beckmann MW, Berchuck A, et al. Network-based integration of GWAS and gene expression identifies a HOX-centric network associated with serous ovarian cancer risk. Cancer Epidemiol Biomarkers Prev. 2015; 24: 1574-84. https://doi.org/10.1158/1055-9965. epi-14-1270.

23. Burton LJ, Dougan J, Jones J, Smith BN, Randle D, Henderson V, Odero-Marah VA. Targeting the nuclear cathepsin L CCAAT displacement protein/cut homeobox transcription factor-epithelial mesenchymal transition pathway in prostate and breast cancer cells with the Z-FY-CHO inhibitor. Mol Cell Biol. 2017; 37. https://doi. org/10.1128/mcb.00297-16.

24. Matei D, Fang F, Shen C, Schilder J, Arnold A, Zeng Y, Berry WA, Huang T, Nephew KP. Epigenetic resensitization to platinum in ovarian cancer. Cancer Res. 2012; 72: 2197 205. https://doi.org/10.1158/0008-5472.can-11-3909. 